\title{
Analysis of HER Family (HER1-4) Expression as a Biomarker in Combination Therapy with Pertuzumab, Trastuzumab and Docetaxel for Advanced HER2-positive Breast Cancer
}

\author{
KOJI TAKADA ${ }^{1}$, SHINICHIRO KASHIWAGI ${ }^{1}$, WATARU GOTO $^{1}$, YUKA ASANO ${ }^{1}$, \\ TAMAMI MORISAKI ${ }^{1}$, HISAKAZU FUJITA ${ }^{2}$, TSUTOMU TAKASHIMA $^{1}$, \\ MASAHIKO OHSAWA ${ }^{3}$, KOSEI HIRAKAWA ${ }^{1}$ and MASAICHI OHIRA ${ }^{1}$ \\ Departments of ${ }^{1}$ Surgical Oncology, and ${ }^{3}$ Diagnostic Pathology, \\ Osaka City University Graduate School of Medicine, Osaka, Japan; \\ ${ }^{2}$ Department of Scientific and Linguistic Fundamentals of Nursing, \\ Osaka City University Graduate School of Nursing, Osaka, Japan
}

\begin{abstract}
Background: Chemotherapy with trastuzumab, pertuzumab and docetaxel (TPD regimen) is now strongly recommended as a treatment option for first-line therapy for advanced human epidermal growth factor receptor (HER)2positive breast cancer. In this study, we analyzed the expression of HER 1-4 proteins, and investigated whether or not their expression was predictive of the response of advanced HER2-positive breast cancer to chemotherapy with the TPD regimen. Patients and Methods: The study consisted of 29 cases in which TPD regimen chemotherapy was carried out from September 2013 to November 2015. The expression levels of estrogen receptor $(E R)$, progesterone receptor (PgR), Ki67, HER1, HER2, HER3 and HER4 were evaluated using immunostaining employing needle biopsy specimens. Results: The overall response rate (ORR) was significantly higher in the HER3-positive group than in the HER3-negative group $(p=0.002)$. In prognostic analysis, the HER3-positive group showed a significant progression-free survival extension over the HER3-negative group ( $p=0.042$, log-rank). In univariate analysis, objective response $(p=0.004$, hazard ratio $(H R)=0.123)$ and positive HER3 expression ( $p=0.023, H R=0.279$ ) significantly contributed to extension of progression-free survival interval. Conclusion: HER3 expression may be a useful factor for predicting the response of HER2-positive breast cancer to chemotherapy with the TPD regimen.
\end{abstract}

Correspondence to: Shinichiro Kashiwagi, MD, Ph.D., Osaka City University Graduate School of Medicine, 1-4-3 Asahi-machi, Abeno-ku, Osaka 545-8585, Japan. Tel: +81 666453838, Fax: +81 666466450, e-mail: spqv9ke9@view.ocn.ne.jp

Key Words: Pertuzumab, trastuzumab, HER2, HER3, breast cancer.
Breast cancer (BC) treatment can now be individualized for different subtypes depending on the tumor biology, with these intrinsic subtypes mainly determined by estrogen signals and human epidermal growth factor receptor 2 (HER2) signals (1). The survival of patients with HER2-BC depends greatly on signal transduction from the HER2 protein (2). Conventionally, HER2 protein expression is a known marker of poor prognosis (2-4). Trastuzumab and other anti-HER2 therapies, however, greatly improve the prognosis for HER2-BC, and HER2 protein expression is now regarded as a highly significant predictive factor for therapeutic effect $(5,6)$. Pertuzumab, which like trastuzumab is a humanized monoclonal antibody, came onto the market in 2012 (7), and the antibody-drug conjugate trastuzumab emtansine has further greatly improved the prognosis for HER2-BC (8). Chemotherapy with the TPD regimen (trastuzumab, pertuzumab and docetaxel) is now strongly recommended as a treatment option for first-line therapy for advanced HER2-BC (9).

Trastuzumab binds to extracellular domain IV of HER2, whereas pertuzumab binds to extracellular domain II of HER2, thereby blocking downstream signal transduction by blocking dimerization with other members of the HER family (7). Pertuzumab blocks signal transduction downstream of HER2 that is activated by the HER3 ligand heregulin more effectively than does trastuzumab (10). This tumor growthinhibiting effect is believed to be due to blocking of the phosphatidylinositol-3 kinase-protein kinase B pathway downstream from HER2 via blocking of the formation not only of HER2-HER2 homodimers but also of HER2-HER3 heterodimers, as well as to the activation of antibodydependent cell-mediated cytotoxicity at a level similar to that of trastuzumab. In experiments in mice engrafted with a human breast cancer cell line with high levels of HER2 
expression, pertuzumab exhibited an equivalent tumor growth-inhibiting effect to that of trastuzumab, and their combined use resulted in a stronger tumor growth-inhibiting effect (11). The addition of pertuzumab has also been shown to inhibit the regrowth of tumors that have grown when treated with trastuzumab alone (11).

The curing of advanced or metastatic BC is difficult, except for a few cases. For this reason, the objective of treatment is commonly the prolongation of survival, with the aim of maintaining the quality of life (12). It is therefore essential to both minimize the rate of adverse events accompanying treatment and to improve the symptoms associated with tumor progression. Moreover, BC is a very diverse disease regarding tumor biology, as stated above, with wide variation among individuals regarding sensitivity to anticancer drugs. Accordingly, in order to achieve maximum results from chemotherapy, it is necessary to predict the efficacy of treatment and select the optimum pharmacotherapy according to the characteristics of both the patient and the tumor. There is therefore a need for the identification of useful biomarkers that are capable of predicting the therapeutic effect when advanced HER2-BC is treated with chemotherapy using the TPD regimen.

We, therefore, hypothesized that given that the mechanism of action of pertuzumab involves the formation of dimers of HER2 with other HER family proteins, HER family expression may be predictive of its therapeutic effect. In this study, we analyzed the expression of HER 1-4 proteins, and investigated whether or not their expression was predictive of the response of advanced HER2-BC to chemotherapy with the TPD regimen.

\section{Patients and Methods}

Patient background. The study consisted of 29 cases in whom TPD regimen chemotherapy was carried out from September 2013 to November 2015 at the Osaka City University Hospital, Osaka, Japan. The median follow-up time was 497 days (range $=91-1015$ days). The overall response rate (ORR), clinical benefit rate (CBR), disease control rate (DCR), overall survival (OS) and progressionfree survival (PFS) were calculated regarding the efficacy of this regimen. Breast cancer was confirmed histologically by core needle biopsy and staged by systemic imaging studies using computed tomography, ultrasonography, and bone scintigraphy. Additionally, based on the immunohistochemical expression of estrogen receptor (ER), progesterone receptor (PgR), HER2 and Ki67, the tumors were categorized into immunophenotypes of luminal A (ER-positive and/or PgR-positive, HER2-negative, Ki67-low), luminal B (ERpositive and/or PgR-positive, HER2-positive: Luminal HER2) (ERpositive and/or PgR-positive, HER2-negative, Ki67-high), HER2 enriched (ER-negative, PgR-negative, and HER2-positive), and TNBC (negative for ER, PgR and HER2) (1).

For the TPD regimen, the loading dose of trastuzumab was 8 $\mathrm{mg} / \mathrm{kg}$ and that of pertuzumab was $840 \mathrm{mg}$. The maintenance dose of trastuzumab was $6 \mathrm{mg} / \mathrm{kg}$ and that of pertuzumab was $420 \mathrm{mg}$ every 3 weeks until disease progression. The dose of docetaxel was $75 \mathrm{mg} / \mathrm{m}^{2} / 3$ weeks for six cycles; however, patients who were not healthy enough for this dose received 60 or $50 \mathrm{mg} / \mathrm{m}^{2}$ of docetaxel as an initial dose. If their doctors decided that it was possible to continue to give docetaxel and reduce cancer, the patients underwent another six cycles, while, if serious side-effects were found, docetaxel was reduced by 20 or $25 \%$ or discontinued. This protocol was repeated until progressive disease (PD) was detected or a severe adverse event requiring discontinuation of the scheduled chemotherapy was noted. The chemotherapy was administered on an outpatient basis in all cases. The antitumor effect was evaluated based on the criterion for therapeutic effects conforming to the Response Evaluation Criteria in Solid Tumors (RECIST) version 1.1 (13).

The morphology of the tumor was evaluated using conventional hematoxylin and eosin staining, and the expression levels of ER, PgR, Ki67, HER1, HER2, HER3 and HER4 were evaluated using immunostaining employing a core needle biopsy specimen obtained prior to the start of chemotherapy with the TPD regimen. The pathological diagnosis was made by several experienced pathologists specialized in cancer.

This study was conducted at the Osaka City University Graduate School of Medicine, Osaka, Japan, according to the Reporting Recommendations for Tumor Marker prognostic Studies (REMARK) guidelines and a retrospectively written research, pathological evaluation, and statistical plan (14). This study was a retrospective chart review study. Written informed consent was obtained from all patients. This research conformed to the provisions of the Declaration of Helsinki of 2013. The study protocol was approved by the Ethics Committee of Osaka City University (\#926).

Immunohistochemistry. Samples taken before administration of the TPD regimen were analyzed. In the case of untreated metastatic BC, the core needle biopsy for diagnosis as BC was analyzed. In recurrent cases, the core needle biopsy for diagnosis as recurrent or the surgical specimen of first-line treatment was analyzed.

Immunohistochemical studies were performed as previously described $(15,16)$. The tumor specimens were fixed in $10 \%$ formaldehyde solution and embedded in paraffin, after which they were cut into $4-\mu \mathrm{m}$-thick sections and mounted on glass slides. The slides were deparaffinized in xylene and heated for 20 minutes in Target Retrieval Solution (Dako, Carpinteria, CA, USA) at $105^{\circ} \mathrm{C}$ and $0.4 \mathrm{~kg} / \mathrm{m}^{2}$ using an autoclave. The specimens were then incubated with $3 \%$ hydrogen peroxide in methanol for 15 minutes to block the endogenous peroxidase activity and were subsequently incubated with $10 \%$ normal goat or rabbit serum to block nonspecific reactions.

Primary monoclonal antibodies directed against ER (clone 1D5, dilution 1:80; Dako), PgR (clone PgR636, dilution 1:100; Dako), Ki67 (clone MIB-1, dilution 1:00; Dako), HER1 (clone EGFR. 25, dilution 1:100; Novacastra Laboratories Ltd., Newcastle upon Tyne, UK), HER2 (HercepTest ${ }^{\mathrm{TM}}$; Dako), HER3 (clone RTJ2, dilution 1:150; Abcam, Cambridge, UK), and HER4 (c-ERBB-4/HER4, polyclonal, dilution 1:120; Lab Vision Corporation, Fremont, CA, USA) were used. The tissue sections were incubated with each antibody for 70 minutes at room temperature or overnight at $4{ }^{\circ} \mathrm{C}$ and were then incubated with horseradish peroxidase-conjugated anti-rabbit or anti-mouse Ig polymer as a secondary antibody [HISTOFINE (PO) $)^{\mathrm{TM}}$ kit; Nichirei, Tokyo, Japan]. The slides were subsequently treated with streptavidin-peroxidase reagent and 
incubated in phosphate-buffered saline-diaminobenzidine and $1 \%$ hydrogen peroxide (v/v), followed by counterstaining with Mayer's hematoxylin. Positive and negative controls for each marker were used according to the supplier's data sheet.

Immunohistochemical scoring. Immunohistochemical scoring was performed by two pathologists. The cut-off value for ER and PgR positivity was $\geq 1 \%$ positive tumor cells with nuclear staining (17). HER2 expression was scored according to the accepted grading system $(0$, no reactivity or membranous reactivity in fewer than $10 \%$ of cells; $1+$, faint/barely perceptible membranous reactivity in $\geq 10 \%$ of cells or reactivity in only part of the cell membrane; $2+$, weak to moderate complete or basolateral membranous reactivity in $\geq 10 \%$ of tumor cells; or $3+$, strong complete or basolateral membranous reactivity in $\geq 10 \%$ of tumor cells). HER 2 expression was considered positive if the immunostaining score was $3+$, or in cases where the score was $2+$ and included gene amplification determined using fluorescent in situ hybridization (FISH). For FISH analyses, each copy of the HER2 gene and its centromere 17 (CEP17) reference were counted. The interpretation followed the criteria of the American Society of Clinical Oncology/College of American Pathologists (ASCO/CAP) guidelines for HER2 IHC classification for BC: considered positive if the HER2/CEP17 ratio was higher than 2.0 (18). A Ki67-labeling index with $14 \%$ of tumor cells with nuclear staining was considered positive $(1,19)$. To evaluate HER1, HER3, and HER4, the four fields that were most stained were at a magnification of $\times 400$. All cancer cells in the fields were classified one by one into 'non-staining', 'weak', 'moderate', 'strong'.

Receiver operating characteristic (ROC) curve analysis was performed to select the most appropriate cut-off values for HER1, HER 3 and HER4 to stratify patients at high risk of malignancyrelated recurrence. The score with the maximum sensitivity and specificity was selected as the optimal cut-off value. For HER1, the rate of weak or stronger staining membrane of tumor cells was evaluated (Figure 1a). In addition, tumor cell cytoplasmic and membranous HER3 and HER4 staining were scored. The rate of moderate or more staining for HER3 and that of weak or more for HER4 was evaluated (20) (Figure 1b and c).

Statistical analysis. Continuous data are reported as the median (range). Statistical analysis was performed using the JMP software package (SAS, Tokyo, Japan). ROC curve analysis was performed to select the most appropriate cut-off values for HER1, HER3 and HER 4 to stratify patients at high risk of malignancy-related recurrence. The relationship between HER1, HER3, and HER4 proteins and overall response was examined using the chi-square test (or Fisher's exact test when necessary) for trends, as appropriate. The Kaplan-Meier method was used to estimate the values of OS and PFS. The OS and PFS values were compared using the log-rank test. PFS was evaluated on a daily basis and was set as the period from the date of treatment commencement to the earlier of the date of death or confirmation of PD. The Cox proportional hazards model was used to compute univariate and multivariate hazard ratios for the study parameters with $95 \%$ confidence intervals (CI) and was used in a backward stepwise method for variate selection in multivariate analysis. In all of the tests, a $p$-value of less than 0.05 was considered statistically significant. Cut-off values for different biomarkers included in this study were chosen before statistical analysis.

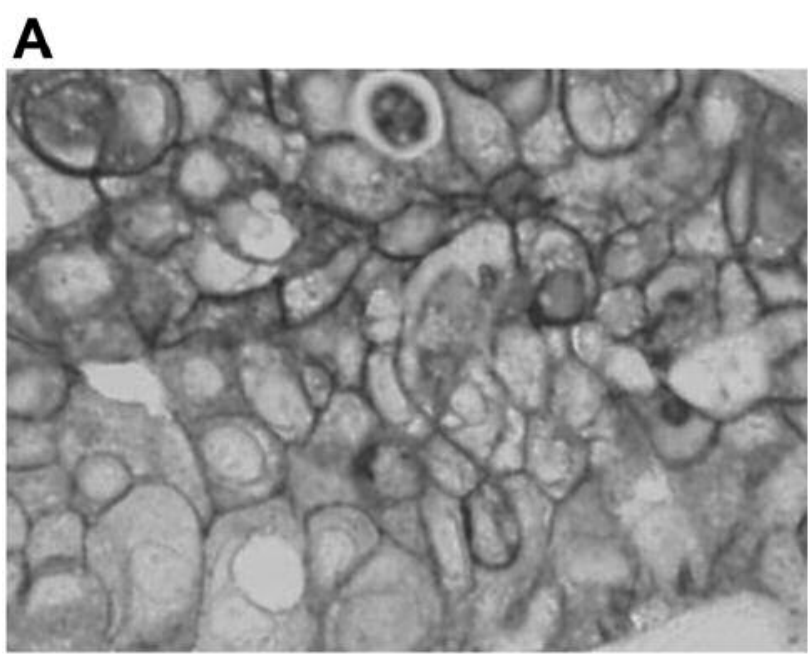

B
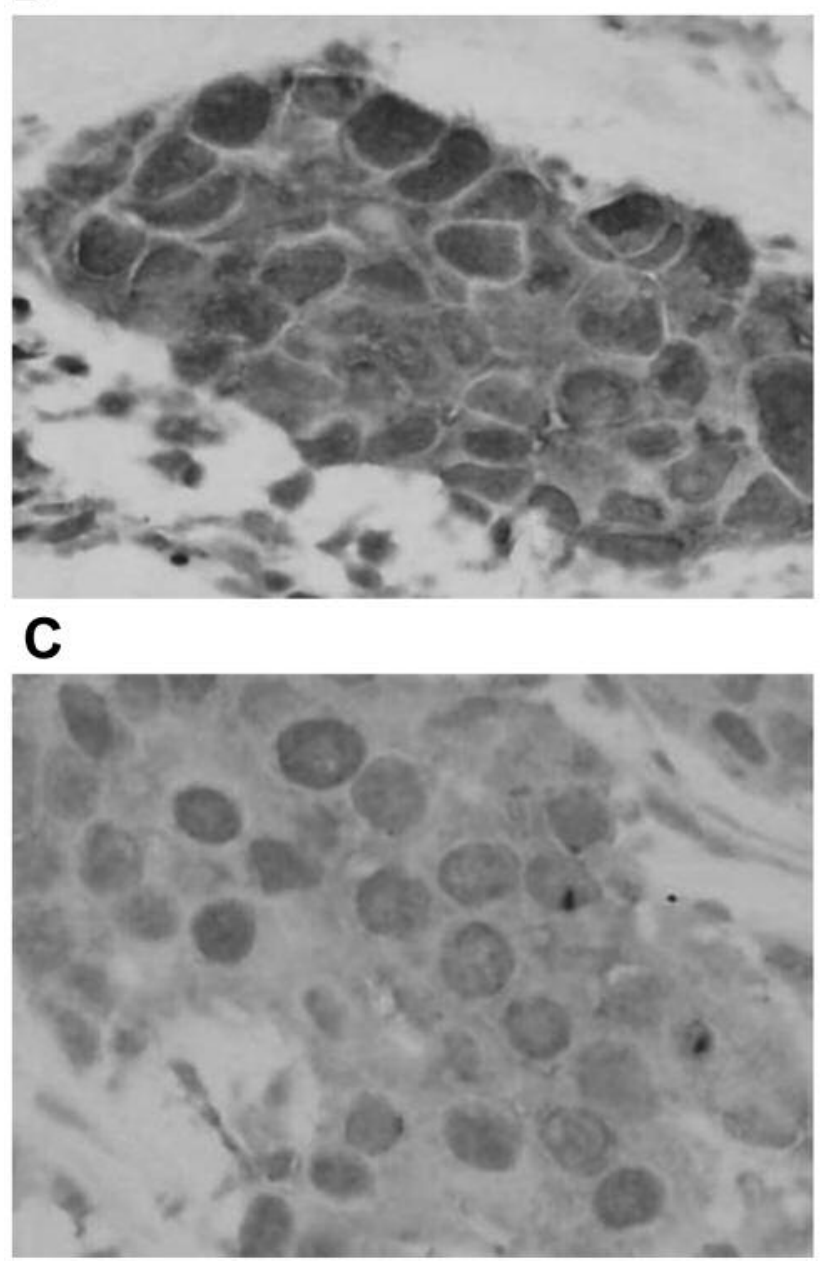

Figure 1. Immunohistochemical determination of human epidermal growth factor receptor (HER)1, HER3 and HER4 (400x). For HER1 (a), the rate of weak or stronger staining membrane of tumor cells was evaluated. In addition, tumor cell cytoplasmic and membranous HER3 (b) and HER4 (c) staining were scored. The rate of moderate or more staining for HER3 and that of weak or more for HER4 was evaluated. 
Table I. Demographical data of 29 patients treated with chemotherapy using trastuzumab, pertuzumab and docetaxel for advanced human epidermal growth factor receptor (HER)-2-positive breast cancer.

\begin{tabular}{|c|c|c|}
\hline Parameters $(\mathrm{n}=29)$ & & Value \\
\hline Age, years & Median (range) & $62(31-78)$ \\
\hline \multirow[t]{2}{*}{ Degree of progression, $\mathrm{n}(\%)$} & Locally advanced & $9(31.0 \%)$ \\
\hline & Visceral metastases & $20(69.0 \%)$ \\
\hline \multirow[t]{3}{*}{ Stage, n (\%) } & III & $3(10.4 \%)$ \\
\hline & IV & $11(37.9 \%)$ \\
\hline & Recurrence & $15(51.7 \%)$ \\
\hline \multirow[t]{6}{*}{ Site of metastases, n (\%) } & Lung & $11(37.9 \%)$ \\
\hline & Bone & $12(41.4 \%)$ \\
\hline & Liver & $7(24.1 \%)$ \\
\hline & Brain & $3(10.3 \%)$ \\
\hline & Lymph node & $11(37.9 \%)$ \\
\hline & Soft tissue & $11(37.9 \%)$ \\
\hline \multirow[t]{2}{*}{ Treatment line, n (\%) } & First & $17(58.6 \%)$ \\
\hline & Other & $12(41.4 \%)$ \\
\hline \multirow[t]{2}{*}{ Estrogen receptor, n (\%) } & Negative & $18(62.1 \%)$ \\
\hline & Positive & $11(37.9 \%)$ \\
\hline \multirow[t]{2}{*}{ Progesterone receptor, n (\%) } & Negative & $20(69.0 \%)$ \\
\hline & Positive & $9(31.0 \%)$ \\
\hline \multirow[t]{2}{*}{ Ki-67, n (\%) } & Negative & $16(55.2 \%)$ \\
\hline & Positive & $13(44.8 \%)$ \\
\hline \multirow[t]{2}{*}{ HER 1, n (\%) } & Negative & $15(51.7 \%)$ \\
\hline & Positive & $14(48.3 \%)$ \\
\hline \multirow[t]{2}{*}{ HER3, n (\%) } & Negative & $10(34.5 \%)$ \\
\hline & Positive & $19(65.5 \%)$ \\
\hline \multirow[t]{2}{*}{ HER 4, n (\%) } & Negative & $15(51.7 \%)$ \\
\hline & Positive & $14(48.3 \%)$ \\
\hline \multirow[t]{2}{*}{ Intrinsic subtype, n (\%) } & HER2-enriched & $17(58.6 \%)$ \\
\hline & Luminal HER2 & $12(41.4 \%)$ \\
\hline
\end{tabular}

TPD: Trastuzumab, pertuzumab, docetaxel.

\section{Results}

Clinical effects of TPD regimen chemotherapy. Twenty-nine patients who underwent chemotherapy using the TPD regimen against inoperable or metastasis/recurrent $\mathrm{BC}$ were included. The gender was female in all cases, with a median age of 62 (range $=31-78$ ) years. A total of 20 patients $(69.0 \%)$ were suffering from visceral metastases at chemotherapy administration. The site of metastasis included, in decreasing order: lung in 11 cases (37.9\%); bone in 12 (41.4\%); liver in $7(24.1 \%)$; brain in three $(20.3 \%)$; lymph node in 11 $(37.9 \%)$; and soft tissue in $11(37.9 \%)$. Regarding intrinsic subtypes, 17 cases $(58.6 \%)$ were the HER2-enriched type, and 12 cases $(41.4 \%)$ were the luminal HER2 type (Table I). The clinical effects of eribulin were as follows: $\mathrm{ORR}=86.2 \%$ (25/29); CBR=89.7\% (26/29); and DCR=93.1\% (27/29). When analyzed according to the intrinsic subtype, the ORR was $88.2 \%(15 / 17)$ in the HER2-enriched cases and $83.3 \%$ (10/12) in the luminal HER2 cases (Table II).
Table II. Clinical effects of chemotherapy with trastuzumab, pertuzumab and docetaxel by breast cancer subtype.

\begin{tabular}{lccc}
\hline & $\begin{array}{c}\text { All breast } \\
\text { cancer }(\mathrm{n}=29)\end{array}$ & \multicolumn{2}{c}{ Intrinsic subtype } \\
\cline { 3 - 4 } & & $\begin{array}{c}\text { HER2-enriched } \\
(\mathrm{n}=17,58.6 \%)\end{array}$ & $\begin{array}{c}\text { Luminal HER2 } \\
(\mathrm{n}=12,41.4 \%)\end{array}$ \\
\hline ORR & $25(86.2 \%)$ & $15(88.2 \%)$ & $10(83.3 \%)$ \\
CBR & $26(89.7 \%)$ & $16(94.1 \%)$ & $10(83.3 \%)$ \\
DCR & $27(93.1 \%)$ & $17(100 \%)$ & $10(83.3 \%)$ \\
CR & $3(10.3 \%)$ & $3(17.6 \%)$ & $0(0 \%)$ \\
PR & $22(75.9 \%)$ & $12(70.6 \%)$ & $10(83.3 \%)$ \\
SD $>24$ weeks & $1(3.4 \%)$ & $1(5.9 \%)$ & $0(0 \%)$ \\
SD & $1(3.4 \%)$ & $1(5.9 \%)$ & $0(0 \%)$ \\
PD & $2(6.9 \%)$ & $0(0 \%)$ & $2(16.7 \%)$ \\
NE & $0(0 \%)$ & $0(0 \%)$ & $0(0 \%)$ \\
\hline
\end{tabular}

ORR: Objective response rate; CBR: clinical benefit response; DCR: disease control rate; CR: complete response; PR: partial response; SD: stable disease; PD: progressive disease; NE: not evaluable; HER: human epidermal growth factor receptor.

HER1, HE 3, and HER4 expression in patients with advanced HER2-positive BC. The HER1, HER3 and HER4 cut-off values for PFS were 28.6 [area under the ROC curve $(\mathrm{AUC})=0.566, \quad 95 \% \quad \mathrm{CI}=0.350-0.782, \quad p=0.559$; sensitivity $=61.11 \%$, specificity $=72.73 \%), 33.9(\mathrm{AUC}=0.533$, $95 \% \quad \mathrm{CI}=0.295-0.775, \quad p=0.753 ; \quad$ sensitivity $=83.33 \%$, specificity $=54.55 \%)$, and $65.4(\mathrm{AUC}=0.629,95 \% \mathrm{CI}=0.424-$ $0.834, p=0.252$; sensitivity $=61.11 \%$, specificity $=72.73 \%$ ), respectively (Figure 2). Of the 29 patients with HER2-BC, 14 $(48.3 \%)$ were in the HER1-positive group, 19 (65.5\%) were in the HER3-positive group, and 14 (48.3\%) were in the HER4- positive group. The ORR was significantly higher in the HER1-positive group than in the HER1 negative group $(p=0.038)$. Similarly, the HER3-positive group had a significantly higher ORR than the HER3-negative group $(p=0.002)$ (Table III). In addition, HER1 expression was significantly correlated with HER3 $(p=0.027)$ and HER4 expression $(p=0.015)$. In prognostic analysis (Figure 3$)$, the HER3-positive group had a significant PFS extension over the HER3-negative group ( $p=0.042, \log$-rank). However, the HER3-positive group showed no significant OS extension over the HER3-negative group ( $p=0.054, \log$-rank). There was no significant difference in PFS and OS between expression level in HER1 and HER4 groups. In univariate analysis, objective response (hazard $\operatorname{ratio}(\mathrm{HR})=0.123$, $p=0.004)$ and positive HER3 expression (HR=0.279, $p=0.023)$ significantly contributed to extension of the PFS interval (Table IV; Figure 4). An objective response was also an independent factor for good prognosis $(\mathrm{HR}=0.205$, $p=0.045$ ) in multivariate analysis; however, positive HER3 expression was not an independent factor in this analysis $(\mathrm{HR}=0.766, p=0.802)$. 
A

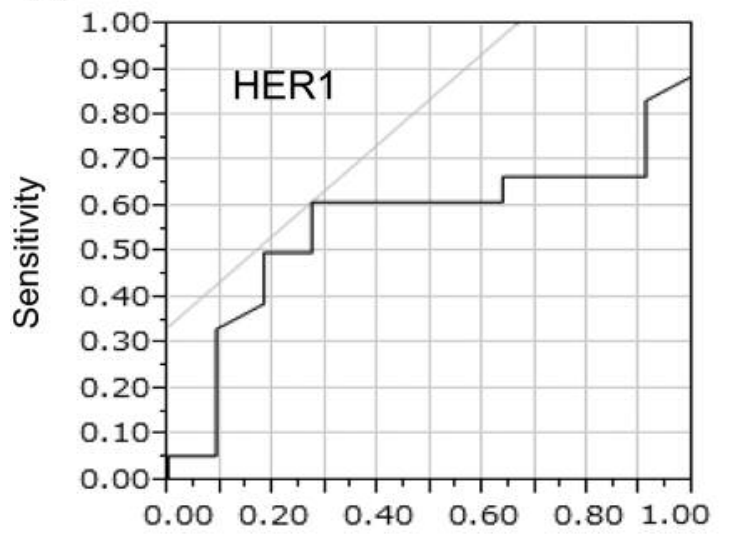

1-Specificity

B

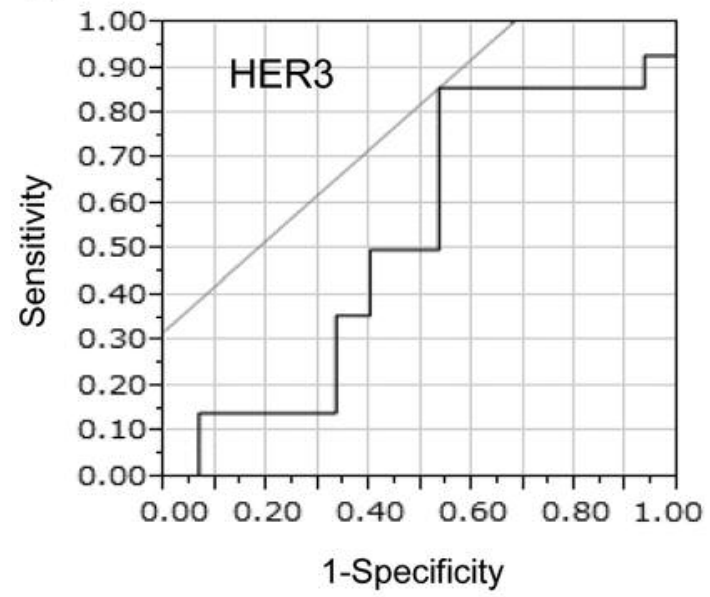

C

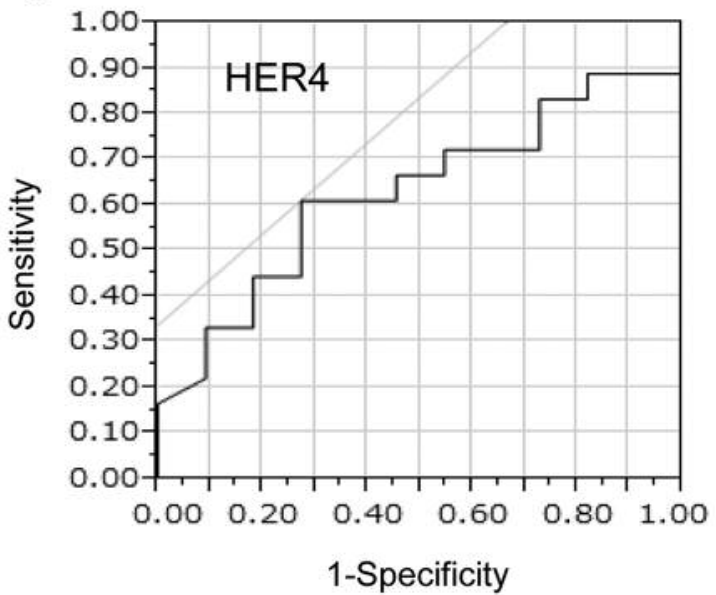

Figure 2. Receiver operating characteristic curve analysis of human epidermal growth factor receptor (HER) expression. The HER1, HER3 and HER4 cut-off values for progression-free survival (PFS) were 28.6 [area under the receiver operating characteristic curve $(A U C)=0.566$; sensitivity $=61.11 \% ;$ specificity $=72.73 \%$ ] (a), $33.9 \quad$ (AUC $=0.533$; sensitivity $=83.33 \%$; specificity $=54.55 \%)(b)$, and $65.4(A U C=0.629$; sensitivity $=61.11 \%$; specificity $=72.73 \%)(c)$, respectively.

\section{Discussion}

The results of the Clinical Evaluation of Pertuzumab and Trastuzumab (CLEOPATRA) trial transformed the treatment strategy for advanced HER2-BC, making chemotherapy with the TPD regimen the first-line treatment $(7,9)$. However, factors other than HER2 that are predictive of sensitivity to anti-HER2 treatment for HER2-BC have yet to be identified, and a search for biomarkers determing which specific subgroups will have improved prognosis by drug therapy targeting HER2 is required. The existence of biomarkers capable of distinguishing those patients for whom the addition of pertuzumab will be more effective would enable expensive drugs to be used more efficiently, making a major contribution to reducing the burden on patients with advanced HER2-BC. However, although a biomarker study carried out as a substudy in the CLEOPATRA trial did investigate serum markers, and the mRNA and protein expression of the HER family receptors and their ligands, no factors were identified as being useful in predicting response to treatment (21). In this study, we analyzed HER1, HER3, and HER4 protein expression and investigated their association with response to chemotherapy with the TPD regimen and prognosis and we identified an association between HER3 expression and both therapeutic effect and prognosis. The difference between our study and the CLEOPATRA trial substudy was the method for determining the cutoff values for immunohistochemical staining. The cutoff values for immunohistochemical analysis used in the CLEOPATRA trial substudy were evaluated in terms of $\mathrm{H}$ scores (21). We also carried out a similar evaluation, and found no significant difference in PFS and OS (data not shown). We therefore used ROC analysis to set the respective cutoff values, and, by using these values we found that HER3 expression to be a significant biomarker for response to TPD therapy.

Following ligand binding, HER family receptors form dimers and exhibit tyrosine kinase activity (22, 23). HER2 is not bound by a specific ligand, but does form dimers and plays a central role as a partner in dimerization either with other members of the HER family (heterodimerization) or with itself (homodimerization), (24). Dimers containing HER2 exhibit strong signal transduction, which is strongest for the HER2-HER3 heterodimer (25). Attention has focused on the expression of HER2-containing dimers (such as the HER2-HER2 homodimer and the HER1-HER2 and HER2-HER3 heterodimers) as factors predictive of the response to anti-HER2 therapy. In experiments using BC cell lines, trastuzumab suppressed cell growth induced by the HER2-HER2 homodimer more strongly than that induced by heterodimers, whereas pertuzumab inhibited that induced by the HER2-HER3 heterodimer more strongly than that induced by the HER2-HER2 homodimer (26). Trastuzumab 
A

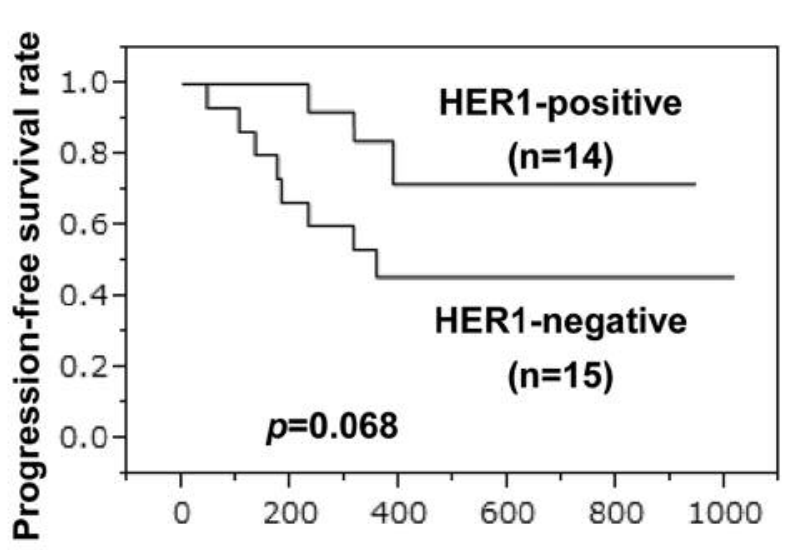

Days after treatment (days)

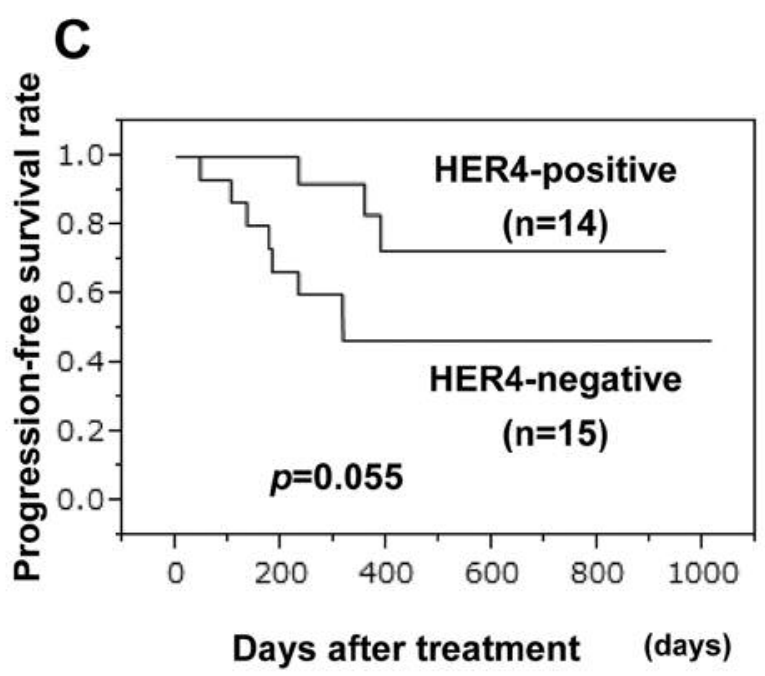

E

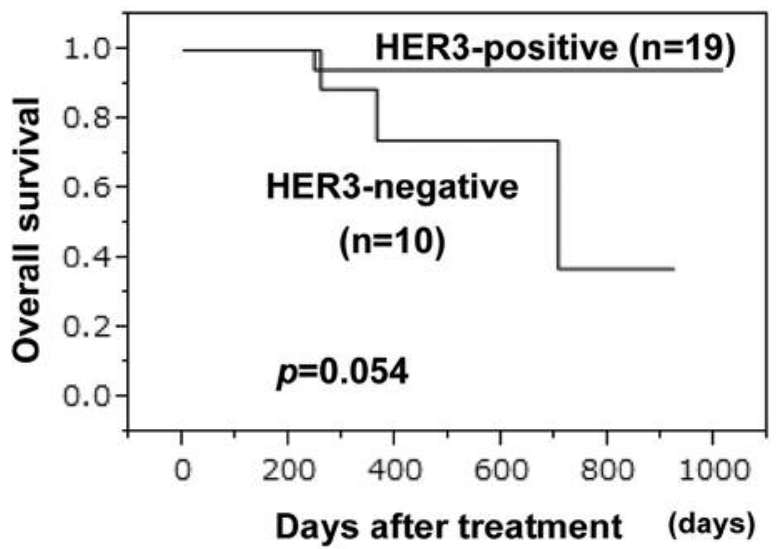

B

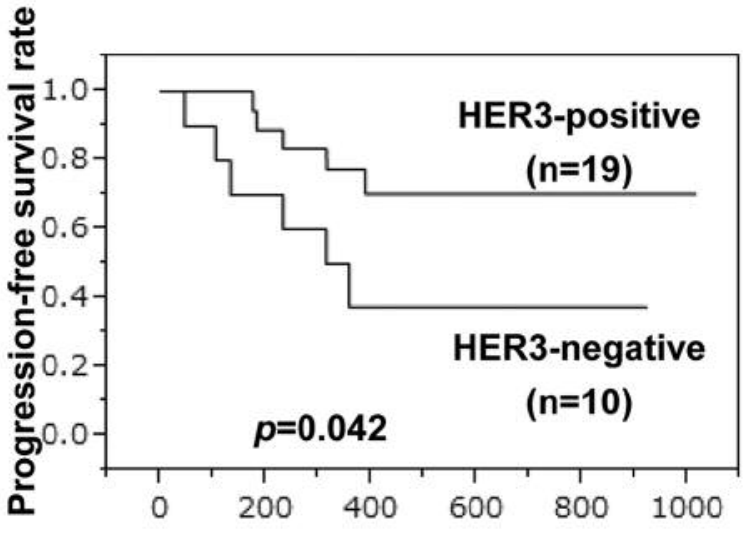

Days after treatment (days)

D

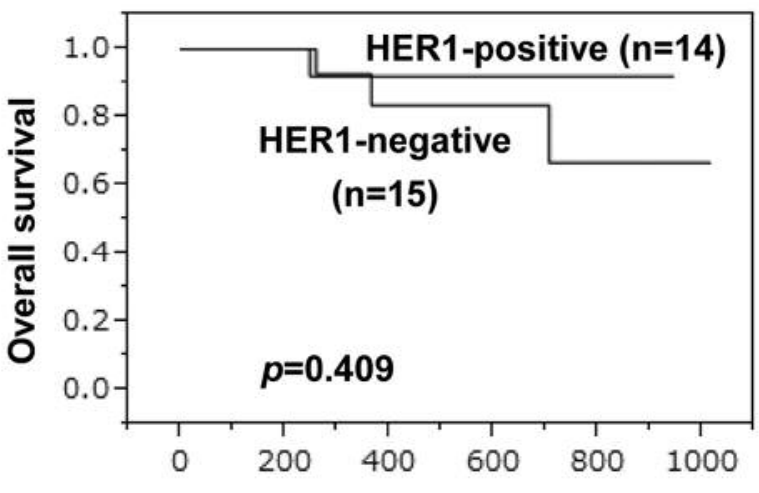

Days after treatment (days)

$\mathbf{F}$

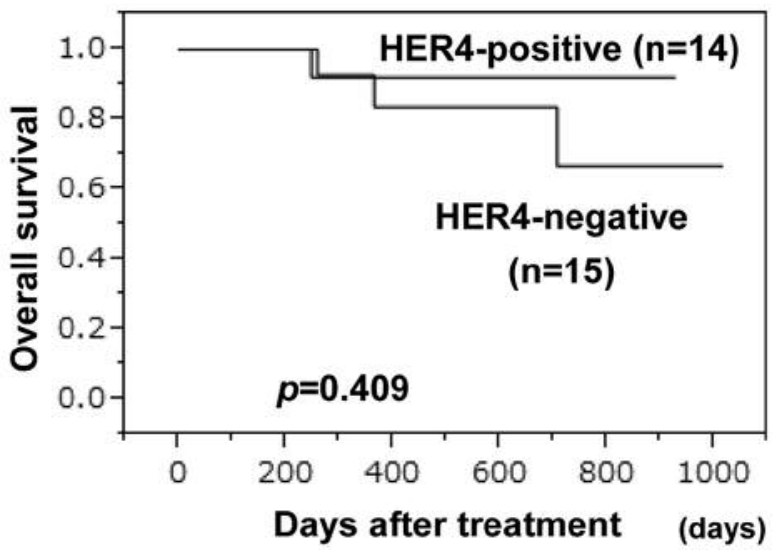

Figure 3. Kaplan-Meier analysis of overall $(O S)(a, c, e)$ and progression-free $(P F S)(b, d, f)$ survival stratified by level of human epidermal growth factor receptor (HER)1, HER3 and HER4 expression in breast cancer. The HER3-positive group showed a significant PFS extension over the HER3negative group $(b)$. However, the HER3 positive group showed no significant OS extension over the HER3 negative group (e). There was no significant difference in PFS and OS in the HERI and HER4 expression level groups $(a, c, d, f)$. Log-rank p-values are shown. 
Table III. Correlation between clinicopathological features and human epidermal growth factor receptor (HER)-1, HER3, and HER4 expression in 29 patients with advanced HER2-positive breast cancer.

\begin{tabular}{|c|c|c|c|c|c|c|c|c|c|}
\hline \multirow[t]{2}{*}{ Parameters } & \multicolumn{2}{|c|}{ HER 1} & \multirow[b]{2}{*}{$p$-Value } & \multicolumn{2}{|c|}{ HER3 } & \multirow[b]{2}{*}{$p$-Value } & \multicolumn{2}{|c|}{ HER4 } & \multirow[b]{2}{*}{ p-Value } \\
\hline & $\begin{array}{c}\text { Positive } \\
(\mathrm{n}=14)\end{array}$ & $\begin{array}{l}\text { Negative } \\
(\mathrm{n}=15)\end{array}$ & & $\begin{array}{c}\text { Positive } \\
(\mathrm{n}=19)\end{array}$ & $\begin{array}{l}\text { Negative } \\
(\mathrm{n}=10)\end{array}$ & & $\begin{array}{c}\text { Positive } \\
(\mathrm{n}=14)\end{array}$ & $\begin{array}{l}\text { Negative } \\
(\mathrm{n}=15)\end{array}$ & \\
\hline \multicolumn{10}{|l|}{ Age at treatment } \\
\hline$\leq 62$ Years & $9(64.3 \%)$ & $6(40.0 \%)$ & 0.204 & $11(57.9 \%)$ & $4(40.0 \%)$ & 0.377 & $9(64.3 \%)$ & $6(40.0 \%)$ & 0.204 \\
\hline$>62$ Years & $5(35.7 \%)$ & $9(60.0 \%)$ & & $8(42.1 \%)$ & $6(60.0 \%)$ & & $5(35.7 \%)$ & $9(60.0 \%)$ & \\
\hline \multicolumn{10}{|l|}{ Degree of progression } \\
\hline Locally advanced & $6(42.9 \%)$ & $3(20.0 \%)$ & 0.197 & $7(36.8 \%)$ & $2(20.0 \%)$ & 0.369 & $6(42.9 \%)$ & $3(20.0 \%)$ & 0.197 \\
\hline Visceral metastases & $8(57.1 \%)$ & $12(80.0 \%)$ & & $12(63.2 \%)$ & $8(80.0 \%)$ & & $8(57.1 \%)$ & $12(80.0 \%)$ & \\
\hline \multicolumn{10}{|l|}{ Stage } \\
\hline IIIC or IV & $7(50.0 \%)$ & $7(46.7 \%)$ & 0.864 & $9(47.4 \%)$ & $5(50.0 \%)$ & 0.897 & $6(42.9 \%)$ & $8(53.3 \%)$ & 0.589 \\
\hline Recurrence & $7(50.0 \%)$ & $8(53.3 \%)$ & & $10(52.6 \%)$ & $5(50.0 \%)$ & & $8(57.1 \%)$ & $7(46.7 \%)$ & \\
\hline \multicolumn{10}{|l|}{ Hormone receptor } \\
\hline Positive & $5(35.7 \%)$ & $7(46.7 \%)$ & 0.566 & $7(36.8 \%)$ & $5(50.0 \%)$ & 0.512 & $4(28.6 \%)$ & $8(53.3 \%)$ & 0.189 \\
\hline Negative & $9(64.3 \%)$ & $8(53.3 \%)$ & & $12(63.2 \%)$ & $5(50.0 \%)$ & & $10(71.4 \%)$ & $7(46.7 \%)$ & \\
\hline \multicolumn{10}{|l|}{ Treatment line } \\
\hline First & $10(71.4 \%)$ & $7(46.7 \%)$ & 0.189 & $14(73.7 \%)$ & $3(30.0 \%)$ & 0.023 & $11(78.6 \%)$ & $6(40.0 \%)$ & 0.036 \\
\hline Other & $4(28.6 \%)$ & $8(53.3 \%)$ & & $5(26.3 \%)$ & $7(70.0 \%)$ & & $3(21.4 \%)$ & $9(60.0 \%)$ & \\
\hline \multicolumn{10}{|l|}{ Ki67 } \\
\hline Negative & $9(64.3 \%)$ & $7(46.7 \%)$ & 0.358 & $11(57.9 \%)$ & $5(50.0 \%)$ & 0.697 & $7(50.0 \%)$ & $9(60.0 \%)$ & 0.604 \\
\hline Positive & $5(35.7 \%)$ & $8(55.3 \%)$ & & $8(42.1 \%)$ & $5(50.0 \%)$ & & $7(50.0 \%)$ & $6(40.0 \%)$ & \\
\hline \multicolumn{10}{|l|}{ HER1 } \\
\hline Negative & ND & ND & & $7(36.8 \%)$ & $8(80.0 \%)$ & 0.027 & $4(28.6 \%)$ & $11(73.3 \%)$ & 0.015 \\
\hline Positive & & & & $12(63.2 \%)$ & $2(20.0 \%)$ & & $10(71.4 \%)$ & $4(26.7 \%)$ & \\
\hline \multicolumn{10}{|l|}{ HER3 } \\
\hline Negative & $2(14.3 \%)$ & $8(53.3 \%)$ & 0.027 & ND & ND & & $2(14.3 \%)$ & $8(53.3 \%)$ & 0.027 \\
\hline Positive & $12(85.7 \%)$ & $7(46.7 \%)$ & & & & & $12(85.7 \%)$ & $7(46.7 \%)$ & \\
\hline \multicolumn{10}{|l|}{ HER4 } \\
\hline Negative & $4(28.6 \%)$ & $11(73.3 \%)$ & 0.015 & $7(36.8 \%)$ & $8(80.0 \%)$ & 0.027 & ND & ND & \\
\hline Positive & $10(71.4 \%)$ & $4(26.7 \%)$ & & $12(63.2 \%)$ & $2(20.0 \%)$ & & & & \\
\hline \multicolumn{10}{|l|}{ ORR } \\
\hline No & $0(0.0 \%)$ & $4(26.7 \%)$ & 0.038 & $0(0.0 \%)$ & $4(40.0 \%)$ & 0.002 & $1(7.1 \%)$ & $3(20.0 \%)$ & 0.333 \\
\hline Yes & $14(100.0 \%)$ & $11(73.3 \%)$ & & $19(100.0 \%)$ & $6(60.0 \%)$ & & $13(92.9 \%)$ & $12(80.0 \%)$ & \\
\hline
\end{tabular}

ND: Not determined ORR: overall response rate. ${ }^{*}$ Chi-square test comparing parameters among positive and negative groups in each HER family.

Table IV. Univariate and multivariate analysis of progression-free survival in 29 patients with advanced human epidermal growth factor receptor (HER)-2-positive breast cancer.

\begin{tabular}{|c|c|c|c|c|c|c|c|}
\hline \multirow[b]{2}{*}{ Parameters } & & \multicolumn{3}{|c|}{ Univariate analysis } & \multicolumn{3}{|c|}{ Multivariate analysis } \\
\hline & & Hazard ratio & $95 \% \mathrm{CI}$ & $p$-Value & Hazard ratio & $95 \% \mathrm{CI}$ & $p$-Value \\
\hline Age at treatment & $\leq 62$ vs. $>62$ years & 1.101 & $0.315-3.679$ & 0.874 & & & \\
\hline Degree of progression & Locally advanced $v s$. visceral metastases & 1.153 & $0.333-5.268$ & 0.832 & & & \\
\hline Stage & IIIC or IV recurrence & 1.481 & $0.447-5.659$ & 0.526 & & & \\
\hline Hormone receptor & Positive $v s$. negative & 0.814 & $0.245-2.833$ & 0.732 & & & \\
\hline Treatment line & First $v s$. other & 1.285 & $0.369-4.278$ & 0.677 & & & \\
\hline Ki67 & Negative $v s$. positive & 0.942 & $0.271-3.129$ & 0.920 & & & \\
\hline HER 1 & Negative $v s$. positive & 0.313 & $0.069-1.085$ & 0.068 & & & \\
\hline HER3 & Negative $v s$. positive & 0.279 & $0.094-0.828$ & 0.023 & 0.802 & $0.195-3.939$ & 0.766 \\
\hline HER4 & Negative $v s$. positive & 0.294 & $0.064-1.024$ & 0.054 & & & \\
\hline Objective response & Yes vs. no & 0.123 & $0.038-0.470$ & 0.004 & 0.205 & $0.039-0.963$ & 0.045 \\
\hline
\end{tabular}

CI: Confidence interval. 


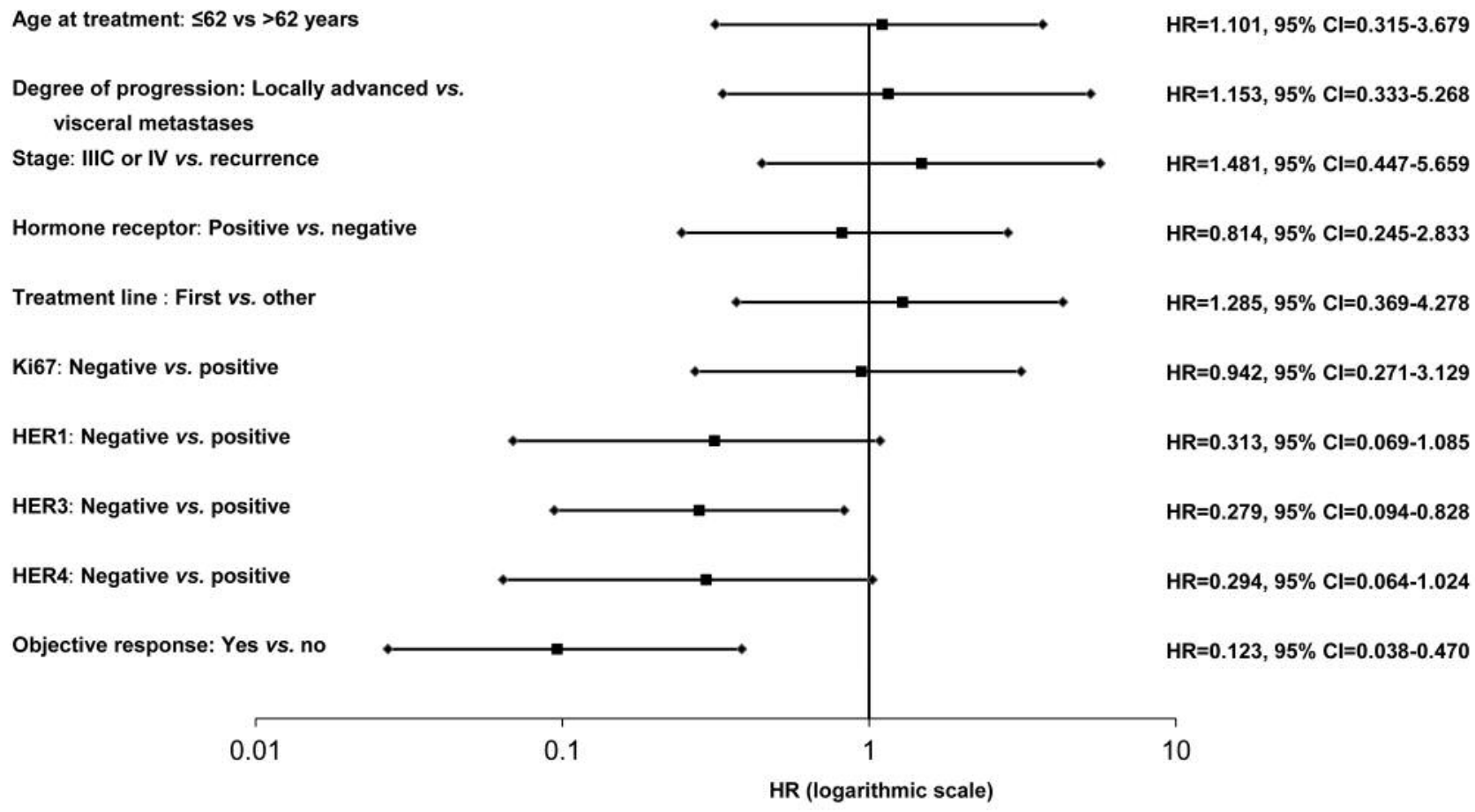

Figure 4. Forest plots of the results of progression-free survival analysis. In univariate analysis, objective response $(p=0.004, H R=0.123)$ and positive human epidermal growth factor receptor $(H E R) 3$ expression $(p=0.023, H R=0.279)$ significantly contributed to extension of the progressionfree survival interval.

has been found to be more effective in the treatment of patients with high levels of expression of the HER2-HER2 homodimer (26), and it is possible that confirmation of HER2-HER3 heterodimer expression may help predict the therapeutic effect of combination chemotherapy with pertuzumab. Our results thus suggest that HER3 expression in HER2-BC may represent a biomarker for predicting the therapeutic effect of combination chemotherapy with pertuzumab. In this study, we found that HER 3 expression can predict the response of advanced HER2-BC to chemotherapy with the TPD regimen.

The coexpression of HER 3 and HER2 is important for BC cell proliferation, and BCs express both HER3 and HER2 (27). In mice, the induction of HER2 overexpression in tumors also increases HER3 expression (28). HER3 signaling is believed to increase in compensation when the signaling of other members of the HER family are blocked (29). However, the clinical significance of HER 3 expression in $\mathrm{BC}$ has not been established, with some studies reporting that it is a poor prognostic factor (30) and others identifying it as a beneficial factor (31). In this study, we found HER3 to be correlated with HER1 and HER4 expression, a result that suggests the existence of crosstalk within the HER family signal network (32). This crosstalk may be connected with resistance mechanisms such as the activation of alternate pathways, and may contribute to the acquisition of resistance to treatment with chemotherapy using the TPD regimen.

The limitations of this study were that it was a retrospective cohort study, and the sample size was small. Nevertheless, we used real-world data based on actual clinical practice, and this study is significant as the first investigation indicating the possibility of HER3 expression as a useful factor for predicting the response of HER2-BC to chemotherapy with the TPD regimen.

\section{Conflicts of Interest}

The Authors have no conflicts of interest to disclose.

\section{Sources of Support}

This study was funded by grants from the Japan Society for the Promotion of Science (KAKENHI, Nos. 25461992, 26461957, and 17K10559) to Shinichiro Kashiwagi.

\section{Acknowledgements}

The Authors thank Yayoi Matsukiyo and Tomomi Okawa (Department of Surgical Oncology, Osaka City University Graduate School of Medicine) for helpful advice regarding data management. 


\section{References}

1 Goldhirsch A, Wood WC, Coates AS, Gelber RD, Thurlimann B, Senn HJ and Panel m: Strategies for subtypes-dealing with the diversity of breast cancer: highlights of the St. Gallen International Expert Consensus on the Primary Therapy of Early Breast Cancer 2011. Ann Oncol 22: 1736-1747, 2011.

2 Slamon DJ, Godolphin W, Jones LA, Holt JA, Wong SG, Keith DE, Levin WJ, Stuart SG, Udove J and Ullrich A: Studies of the HER-2/neu proto-oncogene in human breast and ovarian cancer. Science 244: 707-712, 1989.

3 Chia S, Norris B, Speers C, Cheang M, Gilks B, Gown AM, Huntsman D, Olivotto IA, Nielsen TO and Gelmon K: Human epidermal growth factor receptor 2 overexpression as a prognostic factor in a large tissue microarray series of nodenegative breast cancers. J Clin Oncol 26: 5697-5704, 2008.

4 Slamon DJ, Clark GM, Wong SG, Levin WJ, Ullrich A and McGuire WL: Human breast cancer: correlation of relapse and survival with amplification of the HER-2/neu oncogene. Science 235: 177-182, 1987.

5 Slamon DJ, Leyland-Jones B, Shak S, Fuchs H, Paton V, Bajamonde A, Fleming T, Eiermann W, Wolter J, Pegram M, Baselga $\mathrm{J}$ and Norton L: Use of chemotherapy plus a monoclonal antibody against HER2 for metastatic breast cancer that overexpresses HER2. N Engl J Med 344: 783-792, 2001.

6 Dawood S, Broglio K, Buzdar AU, Hortobagyi GN and Giordano SH: Prognosis of women with metastatic breast cancer by HER 2 status and trastuzumab treatment: an institutionalbased review. J Clin Oncol 28: 92-98, 2010.

7 Baselga J, Cortes J, Kim SB, Im SA, Hegg R, Im YH, Roman L, Pedrini JL, Pienkowski T, Knott A, Clark E, Benyunes MC, Ross G, Swain SM and Group CS: Pertuzumab plus trastuzumab plus docetaxel for metastatic breast cancer. N Engl J Med 366 : 109-119, 2012.

8 Verma S, Miles D, Gianni L, Krop IE, Welslau M, Baselga J, Pegram M, Oh DY, Dieras V, Guardino E, Fang L, Lu MW, Olsen S, Blackwell K and Group ES: Trastuzumab emtansine for HER2-positive advanced breast cancer. N Engl J Med 367: 1783-1791, 2012.

9 Kawajiri H, Takashima T, Kashiwagi S, Noda S, Onoda N and Hirakawa K: Pertuzumab in combination with trastuzumab and docetaxel for HER2-positive metastatic breast cancer. Expert Rev Anticancer Ther 15: 17-26, 2015.

10 Agus DB, Akita RW, Fox WD, Lewis GD, Higgins B, Pisacane PI, Lofgren JA, Tindell C, Evans DP, Maiese K, Scher HI and Sliwkowski MX: Targeting ligand-activated ErbB2 signaling inhibits breast and prostate tumor growth. Cancer Cell 2: 127137,2002

11 Scheuer W, Friess T, Burtscher H, Bossenmaier B, Endl J and Hasmann M: Strongly enhanced antitumor activity of trastuzumab and pertuzumab combination treatment on HER2-positive human xenograft tumor models. Cancer Res 69: 9330-9336, 2009.

12 Hortobagyi GN: Treatment of breast cancer. N Engl J Med 339: 974-984, 1998.

13 Eisenhauer EA, Therasse P, Bogaerts J, Schwartz LH, Sargent D, Ford R, Dancey J, Arbuck S, Gwyther S, Mooney M, Rubinstein L, Shankar L, Dodd L, Kaplan R, Lacombe D and Verweij J: New response evaluation criteria in solid tumours: revised RECIST guideline (version 1.1). Eur J Cancer 45: 228247,2009
14 McShane LM, Altman DG, Sauerbrei W, Taube SE, Gion M, Clark GM and Statistics Subcommittee of the NCIEWGoCD: Reporting recommendations for tumor marker prognostic studies. J Clin Oncol 23: 9067-9072, 2005.

15 Kashiwagi S, Yashiro M, Takashima T, Aomatsu N, Kawajiri H, Ogawa Y, Onoda N, Ishikawa T, Wakasa $\mathrm{K}$ and Hirakawa K: cKit expression as a prognostic molecular marker in patients with basal-like breast cancer. Br J Surg 100: 490-496, 2013.

16 Kashiwagi S, Yashiro M, Takashima T, Aomatsu N, Ikeda K, Ogawa Y, Ishikawa T and Hirakawa K: Advantages of adjuvant chemotherapy for patients with triple-negative breast cancer at stage II: usefulness of prognostic markers E-cadherin and Ki67. Breast Cancer Res 13: R122, 2011.

17 Yamashita H, Yando Y, Nishio M, Zhang Z, Hamaguchi M, Mita K, Kobayashi S, Fujii Y and Iwase H: Immunohistochemical evaluation of hormone receptor status for predicting response to endocrine therapy in metastatic breast cancer. Breast Cancer 13: 74-83, 2006.

18 Wolff AC, Hammond ME, Hicks DG, Dowsett M, McShane LM, Allison KH, Allred DC, Bartlett JM, Bilous M, Fitzgibbons P, Hanna W, Jenkins RB, Mangu PB, Paik S, Perez EA, Press MF, Spears PA, Vance GH, Viale G, Hayes DF, American Society of Clinical $\mathrm{O}$ and College of American P: Recommendations for human epidermal growth factor receptor 2 testing in breast cancer: American Society of Clinical Oncology/College of American Pathologists clinical practice guideline update. J Clin Oncol 31: 3997-4013, 2013.

19 Cheang MC, Chia SK, Voduc D, Gao D, Leung S, Snider J, Watson M, Davies S, Bernard PS, Parker JS, Perou CM, Ellis MJ and Nielsen TO: Ki67 index, HER2 status and prognosis of patients with luminal B breast cancer. J Natl Cancer Inst 101: 736-750, 2009

20 Hirakawa T, Nakata B, Amano R, Kimura K, Shimizu S, Ohira G, Yamada N, Ohira M and Hirakawa K: HER3 overexpression as an independent indicator of poor prognosis for patients with curatively resected pancreatic cancer. Oncology 81: 192-198, 2011.

21 Baselga J, Cortes J, Im SA, Clark E, Ross G, Kiermaier A and Swain SM: Biomarker analyses in CLEOPATRA: a phase III, placebo-controlled study of pertuzumab in human epidermal growth factor receptor 2-positive, first-line metastatic breast cancer. J Clin Oncol 32: 3753-3761, 2014.

22 Barros FF, Powe DG, Ellis IO and Green AR: Understanding the HER family in breast cancer: interaction with ligands, dimerization and treatments. Histopathology 56: 560-572, 2010.

23 Hynes NE and Lane HA: ERBB receptors and cancer: the complexity of targeted inhibitors. Nat Rev Cancer 5: 341-354, 2005.

24 Hudis CA: Trastuzumab - mechanism of action and use in clinical practice. N Engl J Med 357: 39-51, 2007.

25 Alimandi M, Romano A, Curia MC, Muraro R, Fedi P, Aaronson SA, Di Fiore PP and Kraus MH: Cooperative signaling of ErbB3 and ErbB2 in neoplastic transformation and human mammary carcinomas. Oncogene 10: 1813-1821, 1995.

26 Ghosh R, Narasanna A, Wang SE, Liu S, Chakrabarty A, Balko JM, Gonzalez-Angulo AM, Mills GB, Penuel E, Winslow J, Sperinde J, Dua R, Pidaparthi S, Mukherjee A, Leitzel K, Kostler WJ, Lipton A, Bates M and Arteaga CL: Trastuzumab has preferential activity against breast cancers driven by HER2 homodimers. Cancer Res 71: 1871-1882, 2011. 
27 Travis A, Pinder SE, Robertson JF, Bell JA, Wencyk P, Gullick WJ, Nicholson RI, Poller DN, Blamey RW, Elston CW and Ellis IO: C-erbB-3 in human breast carcinoma: expression and relation to prognosis and established prognostic indicators. Br J Cancer 74: 229-233, 1996.

28 Siegel PM, Ryan ED, Cardiff RD and Muller WJ: Elevated expression of activated forms of Neu/ErbB-2 and ErbB-3 are involved in the induction of mammary tumors in transgenic mice: implications for human breast cancer. EMBO J 18: 21492164, 1999.

29 Sergina NV, Rausch M, Wang D, Blair J, Hann B, Shokat KM and Moasser MM: Escape from HER-family tyrosine kinase inhibitor therapy by the kinase-inactive HER3. Nature 445: 437441, 2007.

30 Chiu CG, Masoudi H, Leung S, Voduc DK, Gilks B, Huntsman DG and Wiseman SM: HER-3 overexpression is prognostic of reduced breast cancer survival: a study of 4046 patients. Ann Surg 251: 1107-1116, 2010.
31 Koutras AK, Kalogeras KT, Dimopoulos MA, Wirtz RM, Dafni U, Briasoulis E, Pectasides D, Gogas H, Christodoulou C, Aravantinos G, Zografos G, Timotheadou E, Papakostas P, Linardou H, Razis E, Economopoulos T, Kalofonos HP, Fountzilas G and Hellenic Cooperative Oncology G: Evaluation of the prognostic and predictive value of HER family mRNA expression in high-risk early breast cancer: a Hellenic Cooperative Oncology Group (HeCOG) study. Br J Cancer 99: 1775-1785, 2008.

32 Nahta R, Yu D, Hung MC, Hortobagyi GN and Esteva FJ: Mechanisms of disease: understanding resistance to HER2targeted therapy in human breast cancer. Nat Clin Pract Oncol 3: 269-280, 2006.

Received January 9, 2018

Revised February 5, 2018 Accepted February 13, 2018 